Revista Oficial del Poder Judicial

ÓRGANO DE INVESTIGACIÓN DE LA CORTE SUPREMA DE JUSTICIA DE LA REPÚBLICA DEL PERÚ

Vol. 13, n. ${ }^{\circ} 16$, julio-diciembre, 2021, 269-300

ISSN: 1997-6682 (Impreso)

ISSN: 2663-9130 (En línea)

DOI: 10.35292/ropj.u13i16.470

\title{
Una tradición de Ricardo Palma o cómo Satanás pierde pleitos por desconocer las reglas de interpretación de los contratos
}

\section{A tradition of Ricardo Palma or how Satan loses lawsuits by ignoring the rules of contract interpretation}

0

CARLOS CALDERÓN PUERTAS

Corte Suprema de Justicia de la República

(Lima, Perú)

Contacto: ccalderon@pj.gob.pe

https://orcid.org/0000-0002-9387-166X

\section{RESUMEN}

El autor - valiéndose de una tradición de Ricardo Palma- examina el vínculo contractual surgido entre un viejo escribano de Lima y el diablo. Explora, previamente, la importancia de Palma en la literatura nacional y recoge otras tradiciones posibles de utilizar, para introducir al lector al mundo del derecho. Luego, dentro de un plano característico del derecho en la literatura, utiliza el texto de Palma para abordar de manera específica el tema de la interpretación 
contractual, enlazando los acuerdos que surgen de la tradición «Don Dimas de la Tijereta» con el Código Civil peruano.

Palabras clave: Ricardo Palma; derecho; literatura; Código Civil peruano.

\section{ABSTRACT}

The author - drawing on a tradition of Ricardo Palma - examines the contractual link that arose between an old scribe of Lima and Satan. Previously, he explores Palma's importance in national literature and gathers other traditions that can be used to introduce the reader to the world of law. Then, within a characteristic plane of law in literature, he uses Palma's text to specifically address the issue of contractual interpretation, linking the agreements arising from the «Don Dimas de la Tijereta» tradition with the Peruvian Civil Code.

Key words: Ricardo Palma; law; literature; Peruvian Civil Code.

\section{Recibido: 24/10/2021 Aceptado: 10/11/2021}

\section{INTRODUCCIÓN}

En este escrito se pretende emplear las obras literarias para introducir al lector al mundo del derecho. Se trata de utilizar el texto como pretexto para interpretar el relato y, de esta manera, relacionar la narración y el derecho. Para este propósito, nos valdremos de una tradición de Ricardo Palma, «Don Dimas de la Tijereta. Cuento de viejas que trata de cómo un escribano le ganó un pleito al diablo». Para que quede claro desde el principio, aquí se asume como válido el contrato suscrito entre don Dimas y el demonio. No nos interesa analizar los presupuestos, los elementos del negocio jurídico o los llamados requisitos de validez; lo único que nos importa es el tema de la interpretación de las cláusulas contractuales. 


\section{RICARDO PALMA}

Lima fue fundada por Francisco Pizarro y creada por Ricardo Palma. No hay autor peruano que haya destacado tanto la ciudad como ese hijo de pardo y cuarterona, como se decía entonces. Nació en Lima el 7 de febrero de 1833 y falleció en Miraflores el 6 de octubre de 1919. Circunscribimos sus tradiciones a Lima, pues, aunque se hicieron llamar "peruanas», solo cuando acomete con punzante invención - antes que con árida verdad- los aconteceres de esta ciudad, se siente su inspirado ingenio y su sutil ironía. Riva-Agüero (1962), con señera corrección, expresa:

Me imagino que leídas las Tradiciones fuera de Lima, deben perder muchos de sus méritos; y que, leídas fuera del Perú, perderán la mitad por lo menos de sus hechizos. Pero, para los que hemos nacido en este rincón del mundo y amamos con filial cariño los patrios recuerdos, poseen una magia indefinible (p. 187).

De hecho, la primera de sus tradiciones, «Don Dimas de la Tijereta», si exceptuamos «Palla-Huarcuna», cuya forma no es precisamente la del género que le hizo tan famoso, se asienta en Lima; lo mismo la última, "Una visita al mariscal Santa Cruz», escrita en octubre de 1914, que recuerda el tremendo susto que Santa Cruz se llevó en 1839 en la calle del Rastro de San Francisco, luego de su derrota en Yungay, que puso fin a su sueño de construir la confederación peruano-boliviana, cuando el «iviva!» de un Palma adolescente le hizo creer que había sido reconocido.

Sus amistades y acaso sus silencios llevaron a Palma a ser considerado un nostálgico del virreinato, a pesar de las (no tan) veladas críticas que escondía su obra, no solo a ese período de la historia peruana, sino también al propio esfuerzo republicano. Quien haya leído las cartas que dirigió a Piérola podrá constatar — perdonen el galicismo que acaso lo enfurecería - sus invectivas contra una oligarquía que no creó un Estado en forma y que luego se sumió en la indiferencia ante la derrota insultante por parte del ejército invasor: 
Para mí, señor don Nicolás (y perdones mil por la confianza), tiene usted un solo pecado pero gordo, muy gordo, de esos que no se lavan con toda el agua bendita de la cristiandad: Ese pecado es no haber sido dictador. ¡Qué diablos! Serlo, en forma, o no serlo. El carácter benévolo de usted y, por lo tanto, contemporizador nos ha partido por el eje. Los civilistas son orgánicamente intransigentes y usted se empeñó en obligarlos, a fuerza de beneficios y consideraciones, a transigir. Esa gente respiró, respira y respirará solo ponzoña contra usted. Pudo usted, y no quiso, aplastar a tiempo a los escorpiones (Palma, 1979, p. 47)1.

Que el Romanticismo literario decayera en el Perú de finales del siglo XIX y que los sectores más aristocráticos de Lima se unieran a Palma ${ }^{2}$ complotaron para que olvide sus afectos liberales y se sitúe, más bien, en el lado conservador de la República. Casi coetáneamente, quizás luego de la conferencia en el Ateneo de Lima de 1886 («Arcaísmo implica retroceso: a escritor arcaico,

1 Demostrando las limitaciones de Palma, Kapsoli (2018) se refiere a la lamentable misiva del 8 de febrero de 1881, en la que denuesta de la población indígena con estas palabras: «En mi concepto, la causa principal del gran desastre del 13 está en que la mayoría del Perú la forma una raza abyecta y degradada, que U. quiso dignificar y ennoblecer. El indio no tiene el sentimiento de la patria; es enemigo nato del blanco y del hombre de la costa y, Señor por Señor, tanto le da ser chileno como turco. Así me explico que batallones enteros hubieran arrojado sus armas, en San Juan, sin quemar una cápsula. Educar al indio, inspirarle patriotismo, será obra no de las instituciones sino de los tiempos». Asimismo, las expresiones de Palma en el siguiente fragmento de una carta del 29 de mayo de 1881 casi coinciden con las de Riva-Agüero: "No hay que engañarse: allí palpita secreta y pérfidamente una hostilidad recelosa y siniestra. El indio es rencoroso; aborrece al blanco y al mestizo con toda su alma; procura engañarles y perderles; si no les declara guerra franca es por cobardía. En él, como en todos los esclavos, fermentan odios mortales e inextinguibles» (p. 190).

2 Haya (1985) menciona: «los señoritos de la intelectualidad aristocrática limeña», «troupe de gente distinguida, intelectuales católicos, niños bien y admiradores de apellidos sonoros» (p. 95); mientras que Sánchez (1981) dice: «admiradores del virreinato y la evocación galana» (t. III, p. 956). 
pensador retrógrado»), posiblemente después del famoso discurso del Politeama del 28 de julio de 1888 ( «iLos viejos a la tumba, los jóvenes a la obra!»), y, sin ninguna duda, luego del discurso en el teatro Olimpo del 30 de octubre de 1888 («pero en la prosa reina siempre la mala tradición»), ocurrió la separación con González Prada. La áspera crítica de don Manuel aquí expuesta originó que Palma, a escondidas, remitiera un escrito a El Comercio, cuya autoría fue descubierta y lo situó en una incómoda posición. El debate se extendió desde las letras y las capillas literarias hasta la mirada del país con distintas sensibilidades políticas, y derivó, en 1912, en el célebre cambio en la dirección de la Biblioteca Nacional. Esto ocasionó, primero, el apoyo a Palma por parte de los principales miembros de lo que se dio en llamar la generación del 900; después, la conocida Nota informativa acerca de la Biblioteca Nacional, en la que don Manuel, con dureza singular, exponía los libros faltantes, el mal gusto y el uso de los libros por parte de Palma, como si fueran suyos $^{3}$.

En todo caso, más allá de las magulladuras intelectuales, lo cierto es que mientras González Prada era señalado como el apóstol de las nuevas generaciones (hubo hasta una universidad popular con

3 Se refiere a que el tradicionista estampaba con su sello personal y colocaba notas al margen de los libros. Por ejemplo: «Aparece de este documento que el Virrey Amat era como libertino, muy capaz de fornicar a una lora por el pico» (González Prada, 1912, p. 20). Es inevitable recordar que don Manuel informó a Rufino Blanco Fombona de algunas de las expresiones que Palma colocaba en los libros de aquel. El vuelto lo haría Blanco Fombona (1966) en el prólogo a la segunda edición de Pájinas libres, señalando que el odio de Palma a Bolívar se debía a que descendía de una violación de soldados «negros» venidos con el Libertador: «Don Ricardo ha olvidado, hasta ahora, incluir entre sus Tradiciones peruanas esta amarga tradición de familia. No podemos echárselo en cara. Me alegro que el viejo mulato de Lima pueda leer antes de morirse esta breve nota. Se la debía. No tanto por vindicar la memoria de Bolívar como para corresponder a las acotaciones que él puso, según parece, al margen de alguna obra mía en la Biblioteca Nacional del Perú. Donde las dan las toman» (p. 22). 
su nombre) y recibía el agradecimiento de los nuevos ${ }^{4}$, Palma quedó afincado en lo viejo, lo pasado y la tradición. Acaso por eso, un miembro de esa aristocracia limeña como Riva-Agüero (1962) lo denominó «el representante más genuino del carácter peruano», el «escritor representativo de nuestros criollos», sobrio y burlón, enamoradizo y galante, que, aunque religioso, «no reverencia ciegamente al clero y a la Iglesia», y ha pintado la «faz benigna y pacífica de los conquistadores, que con frecuencia ha sido olvidada y preterida» (p. 191), y el ambiente colonial del siglo XVIII ${ }^{5}$.

Cierto es, no obstante, que ya Riva-Agüero (1962) avizoraba la rebeldía que existía en las páginas de Palma, y con evidente enfado dice:

Es zumbón, satírico, algo escéptico, amablemente irónico [...]. La Colonia no es para (ser) tomada a lo serio, ya lo dije; y al paso que la amamos, nos reímos un poco de ella. Sin embargo, a veces la burla de Palma, por más que sea benigna y suave, llega a destruir la simpatía histórica. Vemos que se encuentra muy desligado de las añejas preocupaciones, y que, a fuerza de estar libre de esas ridiculeces, no las comprende; y una ligera nube de indiferencias y despego se interpone entonces entre el asunto y el escritor (p. 200).

4 Eguren le dedicó un poemario: La canción de las figuras; Chocano, un poema escrito cuyo primer verso iniciaba así: «Tú apóstrofe certero y elocuente»; mientras que Vallejo escribió en Los dados eternos: «Para Manuel González Prada, esta emoción bravía y selecta, una de las que, con más entusiasmo, me ha aplaudido el maestro». Y en política, recibió el agradecimiento de Haya de la Torre y, en menor medida, de José Carlos Mariátegui.

5 Sin embargo, Riva-Agüero no era ajeno a la debilidad de la clase social que dicho ambiente formaba. Dice: «Fatales fueron las consecuencias de este régimen, y hoy desgraciadamente la palpamos: habituó a la indolencia, anuló la actividad y el carácter; debilitó como un perfumado baño tibio» (Riva-Agüero, 1962, p. 197). 
Será, sin embargo, Haya de la Torre ${ }^{6}$ el que con más decidido empeño sostendrá que Palma no representaba ni el colonialismo ni el orden que la República quería guardar. En carta dirigida a Julio Barcos en 1925 y publicada dos años después en Por la emancipación de América Latina, dice: "A don Ricardo Palma, que tuvo gracia y certeza auténticas en sus pinturas coloniales y que, en mi modesto concepto, es el más grande ridiculizador de la época, porque, del virrey al paje, todo cae bajo su punzante ironía» (Haya, 1985, p. 66). Y después:

Personalmente, creo que Palma fue tradicionista, pero no un tradicionalista. Creo que Palma hundió la pluma en el pasado para luego blandirlo en alto y reírse de él. Ninguna institución u hombre de la colonia y aun de la República escapó a las mordeduras tantas veces certera de la ironía, el sarcasmo y siempre el ridículo de la jocosa crítica de Palma. Bien sabido es que el clero católico tuvo en la literatura de Palma un enemigo y que sus Tradiciones son el horror de frailes y monjas (Haya, 1985, p. 95).

Y ya, totalmente exultante, en expresión que Mariátegui consideró exagerada y fruto del entusiasmo de Haya:

Ni Palma ni Prada escaparon al ambiente y a la presión del jesuitismo dominante en las filas civilistas. Pero no importa. Nosotros hemos rescatado a Prada, arrancándolo de los chauvinistas del

6 La idea será recogida por Mariátegui en «El proceso de la literatura». Años después, en Carácter de la literatura del Perú independiente, Riva-Agüero (1962) contestó con acritud a ambos escritores: «Nuestros socialistas, como Mariátegui y Haya, en su impagable actitud de superioridad, creen que hemos admirado y aplaudido a Palma porque preferimos la sonrisa al maltrato tan prolongado. No necesitamos tales mercedes. Las razones de admiración a Palma son muy otras que las políticas y sociales. Que no lo juzguen todo cálculo porque no todos somos como ellos. La colonia puede tener, pasada aquella reacción del XIX y de los relajados o fanáticos del XX, apologías muy vigorosas y el escepticismo burlón de Palma, el cual además puede aplicarse a cualquier época y muy en especial a las presuntuosas y haitianas bufonadas de la nuestra» (p. 200). 
civilismo para entregárselo a la nación que es el pueblo. Lo mismo haremos con Palma, y he ahí una de las tareas de ustedes: arrancarle de la interpretación civilista, liberar su memoria de la maliciosa profanación del espíritu rebelde de su obra, y entregarlo también a la nación, que es el pueblo, al lado de Prada, como intelectuales revolucionarios precursores de nuestra causa presente (Haya, 1985, p. 118).

Exagerado o no, en «El proceso de la literatura», Mariátegui (1994), reparando en el escrito de Haya, indica que una reflexión seria sobre la obra de Palma «descubre lo artificioso y lo convencional» de anexarlo con el género colonialista, al que reconstruía «con un realismo burlón y una fantasía irreverente y satírica» (p. 110). Años más tarde, acogiendo esa misma impresión, Sánchez (1981) lamenta que a Palma se le haya tratado de presentar como conservador «olvidando su liberalismo, su masonería; su adhesión al caudillo Piérola, símbolo del movimiento contra la plutocracia criolla; su irreverencia religiosa; su tradición que es algo diferente al chiste» (t. II, p. 956).

Salazar Bondy, en cambio, es de otra opinión. En un libro lleno de amor por la ciudad, aunque se titule Lima la horrible, sostiene que Palma «resultó enredado por su gracia», no obstante su filiación liberal, y contribuyó, a fuerza del aroma adormecedor de salones y alcobas virreinales, a perpetuar la arcadia colonial, pese a su «inicial propósito satírico, ciertamente demoledor» (Salazar Bondy, 1964, pp. 12-13).

Más allá de esta polémica, lo cierto es que Palma ha sido un referente de la literatura peruana y, en su tiempo, de la literatura americana. Sus tradiciones son un deleite, una invitación a la sonrisa y una censura a nuestras debilidades. Tal es la genialidad de su pluma que algunos textos suyos, pienso, por ejemplo, en «Minucias históricas» $\mathrm{y}$ «El baile de la Victoria», valen tanto o más que un 
tratado sobre historia del Perú que quiera exponer los inicios de la República y la etapa de la consolidación. Así, en la primera de las tradiciones nombradas, Palma (2001) relata el episodio sucedido a Justo Figuerola, el 11 de agosto de 1844, cuando, abrumado por la turba que pedía nuevo gobierno, le dice a su hija que tire la banda por el balcón (p. 1728). En «El baile de la Victoria», esto es, en el homenaje ofrecido a Echenique el 15 de octubre de 1853, Palma expone «el derroche financiero que permitió a descamisados de la víspera ostentar en el baile un lujo deslumbrador e insultante» (p. 1702).

\section{PALMA Y EL MUNDO DEL DERECHO}

Algunas de las tradiciones de Palma pueden ser abordadas desde una mirada jurídica. Un trabajo como este no pretende detallar de manera específica esos vínculos, pero sí hacer referencia a algunos textos. Por ejemplo, en "Mujer y tigre» se relata el asesinato de D. Carlos, concretado por Sebastiana, una especie de Medea colonial, quien narcotiza al antiguo seminarista, ahora casado, y luego de atarlo de manos y pies, llama al hijo de ambos para decirle:

Te quise cuando tu padre fue mi amante. Él me abandonó, burlando mi inocencia, y es esposo de otra mujer, que por él no ha hecho como yo el sacrificio de su honra. Tan vil proceder es el origen del odio que ahora te tengo, en fuerza del que quiero que mueras a presencia de este infame, de quien rechazo conservar prendas que le pertenezcan (Palma, 2001, p. 154).

Luego, procede a matarlo; lo mismo hace con la hija de ambos. Después, «dirigiéndole las más atroces injurias, principió a cortar miembro por miembro el cuerpo de D. Carlos» (Palma, 2001, p. 154).

«Justos y pecadores» puede ser leído como un texto para confrontar las decisiones judiciales realizadas con base en prejuicios. 
Allí, D. Martín es asesinado, luego de visitar a Transverberación, cuando bajaba las escaleras de la casa del maese Ibirijuitanga, tío de esta. En realidad, D. Martín había sido asesinado por el hermano de Engracia de Toledo, a quien había burlado de amores, pero como Ibirijuitanga era hombre "que daba tirria», y Transverberación, "una mujer descocada», la justicia acabó con la vida de aquel y la encerró a ella. Solo años después, a la muerte en olor a santidad de D. Juan, el hermano de doña Engracia, se supo la verdad. Un pequeño pergamino enrollado encontrado entre las pertenencias de este decía así:

Yo, D. Juan Toledo, a quien todos hubisteis por santo, y que usé hábito penitencial, no por virtud sino por dañada malicia, declaro en la hora suprema: que habrá poco menos de veinte años que, por agravios que me hizo D. Martín de Salazar en menoscabo de la honra que Dios me dio, le quité la vida a traición, y después que lo enterraron tuve medios de abrir su sepultura, comer a bocados su corazón, cortarle la cabeza, y habiéndole vuelto a enterrar me llevé su calavera, con la que he andado sin apartarla de mi presencia, en recuerdo de mi venganza y de mi agravio. ¡Así Dios le haya perdonado y perdonarme quiera! (Palma, 2001, p. 191).

«Predestinación» es un claro ejemplo de lo que ahora se llama feminicidio. La tradición relata la historia de María, una actriz guayaquileña que recala en Lima en compañía de Rafael Cebada. Palma (2001) cuenta que los celos de Cebada «se alarmaron, hasta el punto de abofetear a la actriz en el vestuario una noche en que la vio recibir de manos del marqués de C. un precioso ramillete» (p. 202). Entonces, María se liberó de su amante y se fue a vivir con Paca, una bailarina, quien vivía en la mitad de la calle de las Mantas. El día de la fiesta de la Porciúncula, como Rafael Cebada se percató de la presencia de Paca y no de María, fue a buscar a esta, y como ella permanecía inalterable a sus ruegos y amenazas, exclamó: 
«Pues bien, María, si no has de pertenecerme, no quiero que ningún hombre llegue a poseer tu belleza»(Palma, 2001, p. 206), y seis veces le clavó su puñal ${ }^{7}$.

«Un pronóstico cumplido» trata sobre el homicidio del virrey conde de la Nieva por un asunto de malos amores. Lo importante aquí son los ocultamientos de parte de la audiencia para no dar a conocer a los responsables de la muerte debido a su notoriedad en la Lima de entonces. Así, traído como nuevo virrey, el licenciado D. Lope García de Castro, con «el especial encargo de formar el proceso al asesino y sus cómplices», hubo de abstenerse de proseguir con las investigaciones porque los vinculados «eran personajes ricos y de gran significación social». De manera que era mejor que todo permaneciera tal cual, por eso de «quédese esto quedo, que peor es meneallo» (Palma, 2001, p. 257). Esta misma idea se encuentra en «Los duendes del Cuzco. Crónica que trata de cómo el virrey poeta entendía la justicia», en la que un almirante, ufano de su apellido y abusivo de su poder, luego de «darle una soberana paliza al sacerdote», es excomulgado por el párroco de San Jerónimo. El cura se encontraba convencido de que no iba a encontrar justicia en los hombres y dejó un memorial en la iglesia «exponiendo su queja y demandando la justicia de Dios». Tres meses después, su demanda fue atendida y, frente a su casa, se encontró ahorcado al excomulgado. A pesar de las sospechas que recayeron sobre el clérigo, este tenía su «coartada» y la gente del pueblo comenzó a decir que en la noche del crimen avistaron algunos duendes y hechizos. Puesto todo a conocimiento del virrey, su secretario pidió echar una

7 El juicio de Cebada dio origen a una serie de pasquines en las fachadas del cabildo y palacio entre quienes lo defendían y quienes esperaban su condena. Unos decían: «Si una traición desvelada/ contra inocencia dormida/ en tiempo no es castigada,/ muy lejos de arrepentida/ siempre quedará... cebada». Mientras otros afirmaban: «La justicia desvelada/ por la inocencia dormida,/ no quiere sea castigada/ la culpa si arrepentida/ puede quedar no cebada» (Palma, 2001, p. 207). 
«mónita» para hallar la pista de los autores, a lo que el de Esquilache respondió: "Amigo mío, lo hecho está bien hecho: y mejor andaría el mundo si, en casos dados, no fuesen leguleyos trapisondistas y demás cuervos de Temis, sino duendes los que administrasen justicia» (Palma, 2001, p. 298).

De otro lado, el caso de la monja alférez, Catalina Erauzo, es relatado en «¡A iglesia me llamo!». Aquí se describe la fuga de Antonio (como era conocida Catalina) para evitar ser ajusticiado. Lo curioso es que el asilado ingresó al templo de Santa Clara y tuvo que ser remitido, luego de la confesión respectiva, al convento de las abadesas, ocasionando el murmullo general, porque como dice Palma (2001) eso «equivalía a guardar el lobo en el redil de ovejas» (p. 539).

El debido proceso es tratado en «Traslado a Judas. Cuento disparatado de la tía Catita». Allí, el Iscariote, perseguido por sus trapacerías por cuanto territorio había recorrido, llega a Galilea para ser admitido como discípulo de Jesús. Como quiera que no fuera posible atraparlo, Anás y Caifás se contactan con él para localizar al nazareno. Judas recibe las treinta monedas y Jesús es detenido. Como en Jerusalén la expresión general fue censurar su actitud, Judas pregunta a la muchedumbre si conocen de quién hablan y si han oído sus descargos. Al escuchar el no respectivo, Judas se presenta a sí mismo y el pueblo le corre traslado de las acusaciones para que se defienda (Palma, 2001, p. 548).

Un vínculo conyugal resentido se advierte en «El divorcio de la condesita», en el que se cuenta la historia de Marianita Belzunce, a quien se casó, un poco más allá de sus trece años, con D. Juan Dávalos y Ribera, "que pasaba de sesenta octubres y que era más feo que una excomunión» (Palma, 2001, p. 1010). Llegado el día del desposorio, la condesita le dijo a su marido que sería suya cuando tuviera lugar en su corazón, razón por la cual le pidió que hiciera méritos por un año para ver si el amor se podía criar. 
Sin embargo, un día antes de que se cumpliera el plazo fatídico, la condesita se puso en resguardo en la casa de su prima, la abadesa de Santa Clara. Lo que siguió fue asunto de abogados y papel sellado, «y la validez o nulidad del matrimonio no tenía cuándo declararse» (Palma, 2001, p. 1011), ocasionando que aparecieran versos en contra del conde, cuya gracia - la de los cuartetos y no la del empenachado- hace inevitable su transcripción:

Con una espada mohosa y ya sin punta ni filo estate, conde, tranquilo: no pienses en otra cosa. Toda tu arrogancia aborta cuando la pones a prueba: tu espada, como no es nueva, conde, ni pincha ni corta (Palma, 2001, p. 1012).

La muerte de D. Juan puso término al proceso y, probablemente, inició la felicidad de la condesa.

Un litigio curioso es resuelto en «Las justicia de Cirilo». Dos personas compraron una vaca y luego decidieron dividir al animal. Para ello recurrieron a $\mathrm{D}$. Cirilo porque el primero calculó que mejor provecho sacaría de la parte delantera del animal y pidió para sí ese extremo, dejando para el otro la parte de atrás. Suscitado el litigio, D. Cirilo, cual renovado Salomón, o como Sancho en la ínsula Barataria o el Dux en El mercader de Venecia, resolvió:

El documento es terminante y la solución clarísima [...]. El cuidado y gasto de la alimentación corresponde al dueño de la parte delantera, sin que nadie tenga derecho para inmiscuirse en si la vaca comió grano o hierba; y los provechos que son los mamones y la leche de que se elaboran las mantequillas y el queso competen al otro dueño (Palma, 2001, p. 1656). 
Sabemos por Palma (2001), además, que los abogados contamos con un santo - uno solo- en el cielo, llamado San Ibo, «El abogado de los abogados», al que «la Iglesia nos pinta con un gato a los pies, como diciéndonos que al que en pleitos se mete lo menos malo que puede sucederle es salir arañado» (p. 1660).

En «Una sentencia primorosa», Palma se burla de los leguleyos y litigantes sin razón y cuenta la historia de un aragonés de apellido Landázuri que querellaba por el solo hecho del juicio. Cuenta el tradicionista que, agotado de los extravíos de este personaje, D. Domingo del Oro y Portuondo resolvieron una querella en la que Landázuri denunciaba los picos de amor de una parejita de recién vecinos, con estas únicas palabras: «Váyase el recurrente al... "demonio"» (Palma, 2001, p. 1036). Palma (2001) advierte que no fue esa palabra la que se utilizó y asegura que, subido el pleito en apelación, la Real Audiencia del Cuzco, conocida la conducta del litigante, confirmó el apelado y con costas:

Y como a D. Fulano Landázuri, el litigante cócora, no le quedaba otro camino que el de recurrir al Consejo de Indias, y eso era gastadero de muchísima plata, tiempo y flema, se conformó con lo decidido por la Audiencia, satisfizo treinta reales vellón por costas, y (como ustedes lo oyen) sin más reconcomios, DERECHITO, DERECHITO, SE FUE AL... DEMONIO (p. 1036) ${ }^{8}$.

\section{DON DIMAS DE LA TIJERETA}

«Don Dimas de la Tijereta» es una tradición que puede vincularse al campo del derecho civil. Relata el tema de los contratos. No es, por supuesto, el único caso en que la literatura de manera tan explícita se ha entregado con fantasía, humor y también en grado de desventura a circular por dichos predios. Es conocido por

8 Allí Palma dice: «Otra fue la palabrita. Ya la adivinará el lector por poco malicioso que sea». 
todos el tema de El mercader de Venecia y, en tono a lo que pasó con don Dimas, el Fausto de Goethe.

Sin duda se trata de obra de otro empaque y fuego, pero puesto a ver el tema de las obligaciones que surgen entre las partes en la obra de Goethe, solo para quedarse en el triángulo formado por el Señor, Mefistófeles y Fausto - dicho sea de paso, estudiante de filosofía, jurisprudencia, medicina y teología, y, por si fuera poco, magíster y doctor como el propio Goethe-, en el que el Señor, orgulloso de que Fausto no tiene el menor empacho, acepta la apuesta que le propone Mefistófeles de que puede corromper a Fausto. Una especie de obligación que, en términos del Código Civil, acaso debería solucionarse por la vía del juego y la apuesta no autorizados (artículo 1943 del Código Civil), es decir, no exigible y, si se cancela, sin lugar a repetición; o por la vía del juego y la apuesta prohibidos (artículo 1944 del Código Civil), que no da lugar a pretensión alguna, y hasta el pago es considerado nulo. Acaso lo de Job - hasta donde se sabe, la anterior apuesta entre Dios y el diablo- debió resolverse de la misma manera.

El otro aspecto es la relación establecida entre un Fausto que descree de todo y Mefistófeles. En el cuarto de estudio, aquel dice: «¿Tiene también sus leyes el infierno?/ Está muy bien, entonces,/ ¿se podrá con vosotros, señores, hacer pactos?»(Goethe, 2012, p. 64). Leyes hay y formalidades también, hasta el punto de que Mefistófeles le exige a Fausto que el compromiso sea suscrito con unas líneas. En versos con los que se podría hablar de la formalización por escrito de los contratos, Fausto se duele de que no baste la palabra dada y accede a firmar con sangre. Como se sabe, Fausto quiere que Mefistófeles le conceda a Margarita; al hacerlo, la perdición y el dolor la envuelven a esta, y Fausto debe ser condenado. Que el Señor lo salve al final no parece condecirse con los vínculos que emergen de un contrato. 
Sin el dramatismo y la intensidad de la obra de Goethe, y en tono sarcástico y burlón, en «Don Dimas de la Tijereta» asistimos también al encuentro del demonio con un ser humano. No fue esa la única vez que Palma hizo intervenir a Satanás en sus tradiciones. Solo para mencionar dos casos más, en «El cigarrero de Huacho (cuento tradicional sobre unos amores que tuvo el diablo)», un tal Dionisio, quien venía de Purgatorio, una frigidísima mina de Cajamarca, es confundido con el patudo; mientras que en «Dónde y cómo el diablo perdió el poncho, cuento disparatado», Palma nos informa que a Ica le debemos ese honor.

En todo caso, en «Don Dimas de la Tijereta» no es el propio Satanás quien interviene directamente, sino un representante suyo, Lilit, «correvedile de su Majestad Infernal»(Palma, 2001, p. 143). Pero ya se sabe que los actos jurídicos celebrados por el representante recaen en el representado, de modo que en el contrato suscrito entre este y D. Dimas, las partes contratantes fueron el escribano y el demonio. Los términos del acuerdo fueron los siguientes: "Conste que yo D. Dimas de la Tijereta cedo mi almilla al rey de los abismos en cambio del amor y posesión de una mujer. Ítem, me obligo a satisfacer la deuda desde la fecha en tres años» (Palma, 2001, p. 143).

Un contrato, como se advierte, bastante pequeño, pero en el que aparecen las partes, la forma escrita y las prestaciones y las contraprestaciones que se realizarían. Lo que había ocurrido es que D. Dimas se enamoró de la joven Visitación, de veinte años, «con un palmito y un donaire y un aquel capaces de tentar al mismísimo general de los padres bethlemitas» (Palma, 2001, p. 141), y como aquella no accedía a sus requiebros, este invocó a «un diablo cualquiera» para que se llevase su «almilla» a cambio del amor de la caprichosa criatura. 
En efecto, al escuchar Satanás estas expresiones (parece que el demonio como Dios todo lo oye), mandó a su emisario, no sin reparar que D. Dimas tenía tanto desprecio por su alma que le decía «almilla». Firmado el contrato, en un abrir y cerrar de ojos, Visitación cayó prendida de D. Dimas, pero como no hay plazo que no se cumpla, llegados los tres años, fue hora de cumplir con la contraprestación, por lo que Lilit regresó a la tierra y convocó a D. Dimas, quien, para cumplir con lo suyo, se sacó el jubón que llevaba puesto y se lo entregó al demonio.

-Y ¿qué quiere usarced que haga con esta prenda?_¡Toma! Esa prenda se llama almilla, y eso es lo que yo he vendido y a lo que estoy obligado [...]. Repase usarced, señor diabolín, el contrato, y si tiene conciencia se dará por bien pagado (Palma, 2001, p. 144).

Obviamente, esto no satisfizo a Lilit, quien lo transportó al infierno donde, luego del proceso respectivo, probó D. Dimas su derecho y fue devuelto a la tierra.

\section{ALGUNAS PRECISIONES SOBRE LOS CONTRATOS}

Como se ha mencionado en el apartado anterior, no cuestionaremos el fin del contrato y aceptaremos su existencia, su validez y su eficacia, tres categorías distintas que aluden a la presencia del acuerdo de voluntades, a una estructura acorde con el ordenamiento y a los efectos propios del programa diseñado por las partes. Tampoco discutiremos ni la juridicidad ni la patrimonialidad del contrato celebrado entre D. Dimas y el demonio. Sin embargo, que esa no sea nuestra intención no significa que no se tenga que realizar un breve excursus indispensable solo para fijar algunos contenidos. 


\subsection{Los contratos}

Así como Fausto, D. Dimas de la Tijereta suscribió un contrato con el demonio. Conviene precisar que el contrato es una especie del acto jurídico, en esencia «un acto jurídico plurilateral y patrimonial. Es plurilateral, ya que, a diferencia de los actos unilaterales, necesita el concurso de la manifestación de voluntad de varias partes para generar la creación, regulación, modificación o extinción de relaciones jurídicas» (Puente, 2017, p. 29), y es patrimonial porque lo pactado es posible de ser valorizado (indistintamente de si es oneroso o gratuito) (Puente, 2017, p. 29). En buena cuenta, no todo acto jurídico es contrato (el testamento, el matrimonio, el reconocimiento de un hijo, por ejemplo), pero todo contrato necesariamente es acto jurídico, de lo que sigue que las normas que lo regulan también son las de estas.

Dado que todo contrato es un negocio jurídico, es necesario saber que está integrado por presupuestos, elementos y requisitos. Lo que antecede al negocio jurídico son los presupuestos. ¿Cuáles son esos antecedentes indispensables para la construcción del negocio jurídico? Sin duda, los sujetos y el objeto. El sujeto es el «agente capaz» del que hablaba el derogado artículo 140 del Código Civil; o, como dice el Decreto Legislativo n. ${ }^{\circ} 1384$, el sujeto que tiene "plena capacidad de ejercicio». Cuando se habla del objeto, el asunto se complica: supone, como dicen algunos, las relaciones jurídicas que produce el negocio jurídico; o, como dicen otros, el bien materia de la relación jurídica. En todo caso, de este objeto se ha dicho que debe ser lícito, posible y determinable.

Si el presupuesto es un ex ante, los elementos son partes constituyentes del negocio jurídico. La manifestación de la voluntad es el primero de ellos. Es manifestación de voluntad y no declaración de voluntad, en tanto esta última se expresa de manera escrita o verbal, mientras que la primera también, pero a través de un comportamiento concluyente. Una declaración, por tanto, es manifestación 
de voluntad expresa; y un comportamiento concluyente, manifestación de voluntad tácita. De la causa se ha dicho que puede indicar el interés (móvil) de quien celebra el negocio jurídico (causa subjetiva) o la función económica y social del negocio bajo la estructura de la tipicidad (causa objetiva). En cuanto a la forma, se trata de la manera en que se exterioriza la voluntad.

Cada uno de los elementos y los presupuestos contiene determinados requisitos ${ }^{9}$. El artículo 1351 del Código Civil presenta una definición legislativa (y descriptiva) del contrato, cuya disposición nos permite saber lo siguiente:

1. Todo contrato es un acuerdo jurídico, es decir, un acto de voluntad plurisubjetiva que importa una coincidencia de voluntades.

2. Existen dos o más partes, esto es, un «centro de interés homogéneo», que pueden ser naturales, o naturales y jurídicas, o simplemente jurídicas que reglamentan sus intereses.

3. El contrato crea, regula, modifica y extingue obligaciones. En tanto cumple una función económica ${ }^{10}$, constituye un acto finalista y satisface necesidades. Cuando crea, constituye una relación jurídica; cuando regula, interpreta un contrato, precisando sus alcances; cuando modifica, altera el contrato; y cuando extingue, hace cesar los efectos del contrato. Ronquillo (2018) considera que también transfiere relaciones jurídicas, lo que supone trasladar

9 Revisar Beltrán y Campos (2009).

10 Gabrielli (2013) introduce el concepto de «operación económica». En el prólogo de la edición peruana, Morales Hervias y León Hilario señalan: «Para el autor, la causa es la función económica individual (elemento de cohesión de los demás elementos constitutivos del contrato) que sirve para valorar en concreto el contrato en el plano del control del ordenamiento jurídico sobre su licitud y seleccionar los intereses relevantes y concretos en el plano de la administración y la distribución del riesgo ante sobrevivencias. Agregan que el concepto de operación económica permite valorar la organización de los intereses programados y se trata de una categoría relevante para la interpretación de los contratos» (p. 18). 
sus efectos jurídicos de una esfera jurídica a otra; aquí, a diferencia de la creación, hay situación jurídica subjetiva preexistente, como en el caso de la cesión de posición contractual o la cesión de derechos (p. 16).

4. El contrato tiene efecto jurídico patrimonial, lo que significa que cuando se carece de él no se está ante la figura del contrato.

\subsection{La autonomía privada}

El artículo 1354 del Código Civil informa que las partes pueden determinar libremente el contenido del contrato. Por su parte, el artículo 14.2 de la Constitución del Estado refiere que toda persona tiene derecho a contratar con fines lícitos. Tales dispositivos constituyen el marco por el que discurre la autonomía privada, es decir, ese poder de las partes para vincularse entre sí y para determinar el reglamento contractual que consideren apropiado para la satisfacción de sus intereses.

Tal autonomía privada, sin embargo, tiene como límites el orden público y las buenas costumbres (artículo V del Código Civil), los derechos a la regulación (contratos de adhesión) y los derechos de elección. En este último caso, ellos se encuentran sujetos: (i) internamente a no afectar la conciencia ni la formación de voluntad del consumidor (prácticas comerciales coercitivas, actos de engaño y confusión al consumidor, actos de influencia indebida y actos con información incompleta); y (ii) externamente a impedir la capacidad de optar o aprovechar una situación de dependencia (prácticas monopólicas, actos de abuso de la posición de dominio, prácticas colusorias) (Ronquillo, 2018, pp. 22-24).

\subsection{La relatividad de los contratos}

Los contratos - lo dice el artículo 1363 del Código Civil- solo producen efectos entre las partes que los otorgan y sus herederos, 
salvo si el derecho no es transmisible ${ }^{11}$. Se trata del principio de relatividad de los contratos mediante el cual se establece quiénes son los destinatarios de los efectos directos producidos por el contrato.

A esa eficacia directa se une la eficacia refleja del contrato. En ese sentido, los terceros deben respetar los derechos creados, regulados, modificados o extinguidos por quienes celebraron el contrato. Para expresarlo en otros términos, este último vincula a las partes y puede oponer a terceros sus efectos.

Roppo (2001, p. 528) señala que de esta regla se extrae lo siguiente:

1. El contrato no puede imponer obligaciones a terceros.

2. El contrato no puede quitar derechos a terceros ${ }^{12}$.

3. El contrato no puede impedir a terceros adquirir derechos.

4. El contrato no puede atribuir derechos a terceros.

\subsection{La vinculatoriedad: el pacta sunt servanda}

El artículo 1361 del Código Civil prescribe que en los contratos es obligatorio cuanto se haya expresado en ellos, y el artículo 62 de la Constitución del Estado refiere que los términos contractuales no pueden ser modificados por leyes $\mathrm{u}$ otras disposiciones de cualquier clase. Se trata del llamado pacta sunt servanda, esto es, el principio de vinculatoriedad de los contratos que importa la sujeción de las partes con respecto al contrato que han suscrito.

Se debe reparar en que la norma no dice que el "contrato es ley entre las partes», expresión que sí es utilizada en otros ordenamientos legales. Del pacta sunt servanda se extrae que el vínculo no se disuelve por voluntad unilateral, no se modifica por voluntad unilateral ni se disuelve ni modifica por ley.

11 Ya sea por disposición de la ley (mandato, comodato, depósito), por la naturaleza de los derechos o por pacto.

12 Con excepción de la adquisición a non domino y las dobles enajenaciones. 
No obstante, se presentan excepciones:

1. Desistimiento: una de las partes dispone la disolución del contrato. Se trata del derecho potestativo que surge del contrato (mutuo disenso, artículo 1586 del Código Civil, arras penitenciales) o por ley; en este último caso, por autotutela (artículos 1769, 1786 y 1833 del Código Civil), liberación (artículo 1365 del Código Civil) o protección (artículo 59 del Código de Protección y Defensa del Consumidor).

2. Modificaciones judiciales: por ejemplo, en los casos de los artículos 1346 y 1440 del Código Civil ${ }^{13}$.

\section{LA INTERPRETACIÓN DE LOS CONTRATOS}

\subsection{La interpretación de las cláusulas contractuales}

Una muestra clara de que la máxima in claris non fit interpretatio es inexacta y parece inaceptable en el mundo de los contratos es la tradición de Palma aquí presentada. El fallo, como se sabe, fue dictado en el infierno (lo que habla bien del comportamiento judicial de Satanás), y en él se discutió el significado del término "almilla», que el diablo entendió como «alma» en sentido despectivo, mientras que para D. Dimas solo expresaba la vieja prenda utilizada en el siglo XVII.

Para contradecir al demonio, padre de la mentira y de la maldad, se debe tener argumentos bastante destacables para no caer en su encono ni en la injusticia, máxime si D. Dimas era «hombre que a fuerza de dar fe, se había quedado sin pizca de fe» (Palma, 2001, p. 139), y escribano del que se habían apoderado los tres enemigos del alma, y del que se podía recitar estos versos:

13 Ronquillo (2018) desarrolla el tema de manera específica. 
Un escribano y un gato

en un pozo cayeron,

como los dos tenían uñas

por la pared subieron (Palma, 2001, p. 140).

Como es sabido, nuestro Código Civil ha establecido una serie de artículos para regular el fenómeno de la interpretación. Las reglas generales han sido consideradas en los artículos 168, 169 y 170 del Código Civil, mientras que una disposición especial, referida a los contratos, se encuentra en el numeral 1362 del referido cuerpo legal. Disposiciones más específicas, esta vez contra el estipulante, se hallan en los artículos 1382, 1390 y 1401 de dicho código. Como se ha aceptado pacíficamente en el país, las normas interpretativas no son solo máximas lógicas sugeridas por el legislador o meros consejos o directivas, sino normas legales que obligan al intérprete (las partes, los abogados y el juez). ¿Qué se pretende con la interpretación? Por lo pronto, darle un significado jurídicamente relevante al contrato, desde la búsqueda de la intención común de las partes (Bianca, 2007, pp. 429-430).

Entiendo que la interpretación de una cláusula contractual es distinta a la interpretación legal, en principio, por los distintos vínculos que emergen de ellas ${ }^{14}$. No me parece irrazonable señalar -asimilando lo que dice Taruffo (2009) en Páginas sobre justicia civil, en que se refiere a las disposiciones legales- que las cláusulas alcanzan su significado en la actividad interpretativa, más aún

14 En realidad, aun cuando se trata en cualquier caso de comprobar un significado (del contrato o de la ley), las dos operaciones son profundamente diferentes. La interpretación del contrato, en efecto, tiende a comprobar el contenido de un acto de autonomía privada, según la intención de sus autores; mientras que la interpretación de la ley tiende a comprobar el contenido de una regla del ordenamiento, según su función social. La interpretación de la ley genera problemas como el de la constitucionalidad y de la efectividad, extraños a la interpretación del negocio (Bianca, 2007, p. 431). 
cuando «no están formuladas en términos precisos y rigurosos, sino que incluyen términos vagos, conceptos indeterminados o cláusulas generales» (pp. 58-59). Reitero, Taruffo repara en torno a la ley y no a los contratos, pero asumo que toda expresión - la de la ley, la del contrato y la de nuestro comportamiento- requiere interpretación. Ni en la ley ni en el contrato se «descubre» algo preexistente porque no hay un «significado propio» de las palabras. Ellas tienen el significado que el intérprete les otorga. No hay en principio texto «claro» ni «oscuro». Solo después de la interpretación se puede saber eso. La claridad no es propiedad del texto, sino el fruto de la decisión interpretativa (Guastini, 2011, p. 133).

Se podrá advertir ello en los clásicos ejemplos sobre la prohibición de no permitir el acceso a perros en determinados departamentos o la interdicción de no transitar con vehículos por los parques. Estos se encuentran redactados en términos aparentemente claros. No obstante, de inmediato ocasionan el dilema, respectivamente, de saber si es posible que ingrese otro tipo de animal (por ejemplo, un oso) o que discurran triciclos que, como se observa, también constituyen vehículos.

Es obvio que la interpretación no está sujeta al mero arbitrio del intérprete, sino que debe ajustarse a determinadas reglas, ya sean subjetivas, que importan investigar las declaraciones y los comportamientos recíprocos; u objetivas, que implican fijar el significado del contenido del contrato cuando es dudosa la común intención de las partes, y se recurre a prescripciones legales (conservación del acto, tipicidad, equidad) (Bianca, 2007, p. 427).

Como ha reparado Fernández Cruz (2003), nuestro ordenamiento sigue una tendencia subjetiva y solo en casos específicos admite reglas de interpretación objetiva. Este autor, además, distingue entre reglas y concepciones. Las últimas, que también pueden ser subjetivas y objetivas, aluden a la labor interpretativa que se ciñe a aprehender la «común intención de las partes» desde la voluntad 
psicológica de las partes o desde las declaraciones y las conductas de las partes (p. 733). Así, nuestras reglas de interpretación son subjetivas desde una concepción objetiva, que abandona todo hálito psicológico de la voluntad de las partes.

En aras de establecer un procedimiento interpretativo, Fernández Cruz ha diseñado reglas básicas que podrían ser aplicadas (como peldaños en ascenso) para atender las dificultades de la interpretación. Entiende el profesor peruano que «existe un orden de prelación» desde la regla más importante hasta la menos indispensable, cuyo precepto básico es lo declarado y la común intención de las partes; luego, la aplicación de las reglas de la buena fe; enseguida, la interpretación sistemática; $y$, finalmente, la interpretación funcional (Fernández, 2003, p. 735). La estructura es la siguiente:

1. Primera regla: interpretación de la voluntad declarada y la común intención de las partes (artículos 168 y 1362 del Código Civil).

2. Segunda regla: aplicación de las reglas de la buena fe (artículo 1362 del Código Civil).

3. Tercera regla: interpretación sistemática (artículo 169 del Código Civil).

4. Cuarta regla: interpretación funcional (artículo 170 del Código Civil).

La primera regla implica un examen del sentido literal de las estipulaciones, de lo declarado por las partes, pero también de la común intención de estos, que, como se ha señalado, no supone la búsqueda de la voluntad interna (como quiere la teoría voluntarista del acto jurídico), sino del valor objetivo del contrato deducible de las declaraciones y de los comportamientos (Fernández, 2003, pp. 738-753).

La segunda regla significa tener en cuenta la buena fe, ese modelo de conducta ético-social que tiene un aspecto negativo o de veto, en cuanto rechaza una conducta deshonesta, y otro positivo, en cuanto 
impone una conducta de colaboración; y que, en el caso de la interpretación, importa la valoración de usos sociales y la atención del «prototipo de conducta social media» (Fernández, 2003, p. 775).

La tercera regla atañe a una interpretación sistemática en el entendido de que todo acto jurídico es un todo integral, una unidad indivisible.

Finalmente, debe promoverse una interpretación finalista, de manera que, si existen estipulaciones contradictorias, hay que armonizarlas; y, si ella no fuera posible, la cláusula accesoria deberá ser sacrificada para la conservación del acto jurídico, siempre teniendo en cuenta que los sujetos realizan actos jurídicos para que produzcan efectos, por lo que debe buscarse el fin económico y social perseguido por las partes.

\subsection{La «almilla» de don Dimas de la Tijereta}

Cualquier interpretación, por lo menos en la fase preliminar, inicia en el texto. El contrato suscrito por Lilit, en representación de Satanás, y D. Dimas de la Tijereta decía lo siguiente: «Conste que yo D. Dimas de la Tijereta cedo mi almilla al rey de los abismos en cambio del amor y posesión de una mujer. Ítem, me obligo a satisfacer la deuda desde la fecha en tres años» (Palma, 2001, p. 143).

En la línea expresada por Fernández Cruz (2003), el criterio prescrito en el artículo 168 del Código Civil tiene un claro tinte objetivista, desde que se "prioriza la voluntad declarada sobre la voluntad interna del declarante» (p. 738). Esto supone recurrir al texto que se va a interpretar como límite de lo que debe ser interpretado. Por ejemplo, la palabra «manzana» puede hacer referencia a una fruta, pero también a una cuadra, el pecado o las computadoras; empero, más allá de lo que se quiera decir, la expresión desde la que se parte es «manzana».

Hay que tener claro que la norma aludida contiene dos supuestos de hecho, que Lohmann (citado por Vidal, 1989, p. 220) 
considera que contiene dos mandatos: lo que debe ser materia de interpretación (la palabra «almilla») y la manera de hacerlo, que se logrará con base en la determinación de la común intención de las partes, deducibles de las declaraciones y los comportamientos de estos. Por consiguiente, el artículo 168 del Código Civil no solo hace referencia a la interpretación literal, sino a una que también valora el comportamiento integral de las partes. Al respecto, Betti (2000) señala:

[El] objeto de la interpretación [...] no es la voluntad interna, haya sido manifestada o bien quede sin expresión, sino la declaración o el comportamiento, encuadrados en el marco de circunstancias que les confiere significado y valor. En verdad, lo que cuenta no es tanto el tenor de las palabras o la materialidad del comportamiento, como la situación objetiva en la que aquellas vienen pronunciadas o suscritas y este es mantenido; aquel conjunto de circunstancias, podríamos decir, en el que la declaración y el comportamiento encuentran su natural emplazamiento y donde adoptan, según la estimación de la conciencia social, su típico significado y relieve (p. 289).

Así, la interpretación que propone D. Dimas (finalmente aceptada por Satanás) solo se ciñe a la mera literalidad del término «almilla», pero no se detiene a buscar «su típico significado y relieve». Si el Maligno fuera un sastre, probablemente la interpretación sería distinta, pero no lo es. Es el tentador, el contendor de Dios, su gran adversario, el recogedor de almas para poblar el infierno. Solo de una interpretación limitada e inexacta se podía colegir de «almilla» el significado que finalmente se le otorgó. Es más, dado el pedido existente (la conquista amorosa), el plazo de la prestación y la propia invocación al demonio, ¿era razonable que don Dimas solo se vinculara para otorgar como pago un jubón viejo y usado? ¿El negocio del demonio es arrebatar almas o vender ropa de segunda mano? 
Si el Enemigo hubiera estado en el país, hubiese podido invocar el segundo supuesto de hecho del artículo 168 del Código Civil, vinculado al numeral 1362 del mismo cuerpo legal: «los contratos se negocian, se celebran y se ejecutan según las reglas de la buena fe y la común intención de las partes». De tal expresión surge la necesidad de examinar el comportamiento de las partes en todo el íter contractual (Fernández, 2003, p. 748).

En esa perspectiva, el comportamiento del demonio tiene un único fin que se evidencia en las palabras que Palma (2001) registra: «Ve, Lilit, al cerro de las Ramas y extiende un contrato con un hombre que allí encontrarás y que abriga tanto desprecio por su alma que la llama almilla» (p. 143, las cursivas son nuestras). Que pasados los tres años del contrato haya enviado otra vez a Lilit para el recojo del alma ratifica lo señalado.

Lo mismo puede decirse de D. Dimas: en un mundo vigorosamente católico decide pactar con el demonio, y no lo hace solicitando acrecimientos materiales, sino el amor de Visitación, que según Palma (2001) a veces lo recibía canturriando: «No pierdas en mí balas,/ carabinero,/ porque yo soy paloma/ de mucho vuelo./ Si quieres que te quiera/ me has de dar antes/ aretes y sortijas/blondas y guantes» (p. 42). A esos pedidos cedía D. Dimas, por lo que es inaceptable aceptar que con una mera «almilla» quisiera cancelar su prestación, cuando lo que gastaba era en «aretes y sortijas».

La segunda regla de interpretación señalada por Fernández Cruz alude a la buena fe. Hablar de ella, en el contexto de un cartulario embustero, de trocatintas y de nada menos que el demonio, parece imposible. Sin embargo, no lo es en tanto que resulta irrelevante la conducta de las partes que no se encuentren vinculadas con el contrato. Así, la buena fe que se examina es la que se desarrolló para realizar el negocio y que exige determinar el uso social (Fernández, 2003, p. 755). No abundaremos en este tema porque a ello hemos hecho referencia en párrafos anteriores. 
Aunque Palma se cuida de dar todos los pormenores del contrato, lo que se sabe de este es que contiene, por lo menos, dos cláusulas: la primera, la entrega de la «almilla» por el amor y la posesión de Visitación; la segunda, el plazo de pago. Una interpretación sistemática impone contrastar la cláusula dudosa («almilla») con la siguiente disposición. Si ello es así, la compulsa de ambas cláusulas permite inferir que, salvo que la «almilla» estuviera hecha con hilos de oro, no es razonable concluir que por el amor de una mujer y la "posesión» de ella — situación absolutamente grotesca y delincuencial - se pudiera contemplar un pago como el que don Dimas quiso efectuar.

Si se necesita seguir con otra regla interpretativa, la que nos ofrece el artículo 170 del Código Civil desembocaría en lo mismo. ¿Cuál fue el propósito práctico del contrato? Satisfacer la concupiscencia de un anciano que tenía la estampa de herejía. Para asunto tan grave y complicado, D. Dimas invocó nada menos que a un demonio cualquiera. Tal era su grado de desesperación que no tuvo reparo en ello. Tal era su intención de perderse que ignoró la paz divina y se entregó al regocijo momentáneo del cuerpo para dar su alma después, algo así como, dirá Palma tantas otras veces, entregar a Dios los huesos mientras la carne se dio al diablo. También una interpretación final del contrato nos llevaría a concluir que fue la entrega del «alma» y no de la «almilla» la prestación que debió cumplir el viejo escribano.

\section{CONCLUSIONES}

1. Siguiendo las Tradiciones de Palma, es posible que el cielo no esté plagado de abogados y que, en cambio, estos abunden en el infierno. Por alguna razón que se me escapa, los letrados no quisieron asistir al demonio en este disparatado encuentro con D. Dimas de la Tijereta, quizás porque tienen una especialidad 
distinta a la del derecho civil o, de repente, porque los civilistas optaron por abstenerse, dado que el diablo no paga. Lo cierto es que si este hubiera sido asistido, ese proceso - que dicho sea de paso se realizó con todas las garantías de ley- habría culminado con sentencia distinta. Sin duda, debe haber existido una mala defensa, pero ¿qué jueces fueron los que le dieron la razón al escribano?, ¿qué hacían en el infierno? Es posible cuestionar su decisión, que no tuvo en cuenta los criterios de interpretación contractual que debieron haber conocido cuando andaban por este mundo.

2. Más lástima da el pobre diablo, que incluso cuando gana es un perdedor eterno. Fue expulsado del paraíso casi al inicio de los tiempos; no pudo corromper a Job; y cuando desvió de su camino a Fausto, el Señor rompió las reglas del juego. Su drama es tan intenso que ni siquiera pudo buscar un abogado que pudiera defenderlo adecuadamente de las pretensiones de D. Dimas de la Tijereta. Da tanta pena que quizás, como dice Papini (1954), está cerca de pensar que se trata de «la criatura más horriblemente desdichada de toda la creación» (p. 20); y que algo hay que hacer (¿comprenderlo?, ¿no juzgarlo?, ¿tentarlo?) para que en su agonía infinita no sea objeto de las crueles burlas de la humanidad, y pueda, al fin, encontrar su propia redención.

\section{REFERENCIAS}

Beltrán, J. y Campos, H. (2009). Breves apuntes sobre los presupuestos y elementos del negocio jurídico. Derecho \& Sociedad, (32), 198-211. https://revistas.pucp.edu.pe/index.php/derechoysocie $\mathrm{dad} /$ article/view/17426

Betti, E. (2000). Teoría general del negocio jurídico. Comares. 
Bianca, M. (2007). Derecho Civil 3. El contrato. Universidad Externado de Colombia.

Blanco, R. (1966). Crítica de la obra de González Prada. Fondo de Cultura Popular.

Fernández, G. (2003). Introducción al estudio de la interpretación en el Código Civil peruano. En León, L. (comp.), Estudios sobre el contrato en general (pp. 675-712). ARA Editores.

Gabrielli, E. (2013). Estudios sobre teoría general del contrato. Jurista Editores.

Goethe, J. von (2012). Fausto. Libros del Zorro Rojo.

González Prada, M. (1912). Nota informativa acerca de la Biblioteca Nacional. Imprenta Arica.

Guastini, R. (2011). Disposición vs. norma. En Pozzolo, S. y Escudero, R. (eds.), Disposición vs. norma (pp. 133-156). Palestra Editores.

Haya, V. R. (1985). Obras completas: Tomo I. Por la emancipación de América Latina. Juan Mejía Baca.

Kapsoli, W. (2018). La correspondencia entre Ricardo Palma y Nicolás de Piérola. Aula Palma, 17(17), 35-58. https://revistas. urp.edu.pe/index.php/Aula_Palma/article/view/2121/2144

Mariátegui, J. C. (1994). 7 ensayos de interpretación de la realidad peruana. Amauta.

Palma, R. (1979). Cartas a Piérola (sobre la ocupación chilena de Lima). Carlos Milla Batres.

Palma, R. (2001). Tradiciones peruanas. Océano.

Papini, G. (1954). El diablo. Emecé Editores.

Puente, M. de la (2017). El contrato en general (t. 1). Palestra Editores. Riva-Agüero, J. de la (1962). Carácter de la literatura del Perú independiente. Pontificia Universidad Católica del Perú. 
Ronquillo, J. (2018). La resolución de los contratos: problemas legislativos y jurisprudenciales del incumplimiento contractual. Gaceta Jurídica.

Roppo, V. (2001). El contrato. Gaceta Jurídica.

Salazar Bondy, S. (1964). Lima la horrible. Era.

Sánchez, L. A. (1981). La literatura peruana. Derrotero para una historia cultural del Perú. Juan Mejía Baca.

Taruffo, M. (2009). Páginas sobre justicia civil. Marcial Pons.

Vidal, F. (1989). El acto jurídico en el Código Civil peruano. Cultural Cuzco S. A. 